\title{
Cerebral Aneurysms in Judicial Precedents
}

\author{
Kyeong-Seok Lee, M.D., Jae-Jun Shim, M.D., Jae-Hyun Shim, M.D., Jae-Sang Oh, M.D., Seok-Mann Yoon, M.D. \\ Department of Neurosurgery, Soonchunhyang University Cheonan Hospital, Cheonan, Korea
}

Objective : From November 30, 2016, the Korean Government carried the revised Medical Dispute Mediation and Arbitration Act into effect. Mediation will start automatically without agreements of the defendant, when the outcome of the patient was death, coma more than a month or severe disability. Cerebral aneurysm has a definite risk of bad outcome, especially in the worst condition. Any surgical intervention to this lesion has its own high risk of complications. Recently, Seoul central district court decided $50 \%$ responsibility of the doctors who made a rupture of the aneurysm during coiling (2015Ga-Dan5243104). We reviewed judicial precedents related to cerebral aneurysms in lawsuit using a web search.

Methods : We searched judicial precedents at a web search of the Supreme Court, using the key words, "cerebral aneurysm".

Results : There were 15 precedents, six from the Supreme Court, seven from the High Court, and two from district courts. Seven precedents were related to the causation analysis, such as work-relationship. Five precedents were malpractice suits related bad results or complications. Remaining three precedents were related to the insurance payment. In five malpractice precedents, two precedents of the Supreme Court reversed former two precedents of the High Court.

Conclusion : Judicial precedents on the cerebral aneurysm included not only malpractice suits, but also causation analysis or insurance payment. Attention to these subjects is needed. We also need education of the independent medical examination. To avoid medical disputes, shared decision making seems to be useful, especially in cases of high risk condition or procedures.

Key Words : Cerebral Aneurysm · Negotiating · Causality · Expert Testimony · Malpractice.

\section{INTRODUCTION}

From November 30, 2016, the Korean Government carried the revised Medical Dispute Mediation and Arbitration Act into effect. Mediation will start automatically without agreements of the defendant, when the outcome of the patient was death, coma more than a month or the first grade disability defined in the welfare law for the disabled. Cerebral aneurysm has a definite risk of bad outcome, especially when the patient were in the worst condition. Any surgical intervention to this lesion has its own high risk of complications. Nearly 1/5 of neurosurgeons faced a malpractice claim annually, which is the highest among all medical specialties in USA ${ }^{2,7}$. Recently, Seoul central district court decided responsibility of the doctors who made a rupture of the aneurysm during endovascular coiling (2015Ga-Dan5243104). In a report of malpractice allegation in 280 closed cases $^{10)}$, cerebral aneurysms consisted of about $5 \%$. We reviewed judicial precedents related to cerebral aneurysms in lawsuits using a web search.

-Received : April 19, 2017 •Revised : August 11, 2017 •Accepted : September 13, 2017

-Address for reprints : Kyeong-Seok Lee, M.D.

Department of Neurosurgery, Soonchunhyang University Cheonan Hospital, 31 Soonchunhyang 6-gil, Dongnam-gu, Cheonan 31151, Korea

Tel : +82-41-570-3652, Fax : +82-41-572-9297, E-mail : ksleens@sch.ac.kr

This is an Open Access article distributed under the terms of the Creative Commons Attribution Non-Commercial License (http://creativecommons.org/licenses/by-nc/4.0) which permits unrestricted non-commercial use, distribution, and reproduction in any medium, provided the original work is properly cited. 


\section{MATERIALS AND METHODS}

We searched judicial precedents at a web search of the Supreme Court (http://glaw.scourt.go.kr/wsjo/intesrch/sjo022. do), using the key words, "cerebral aneurysm". There were 15 precedents; six from the Supreme Court, seven from the High Court, and two from district courts. We reviewed these 15 precedents.

\section{RESULTS}

Seven precedents were related to the causation analysis, such

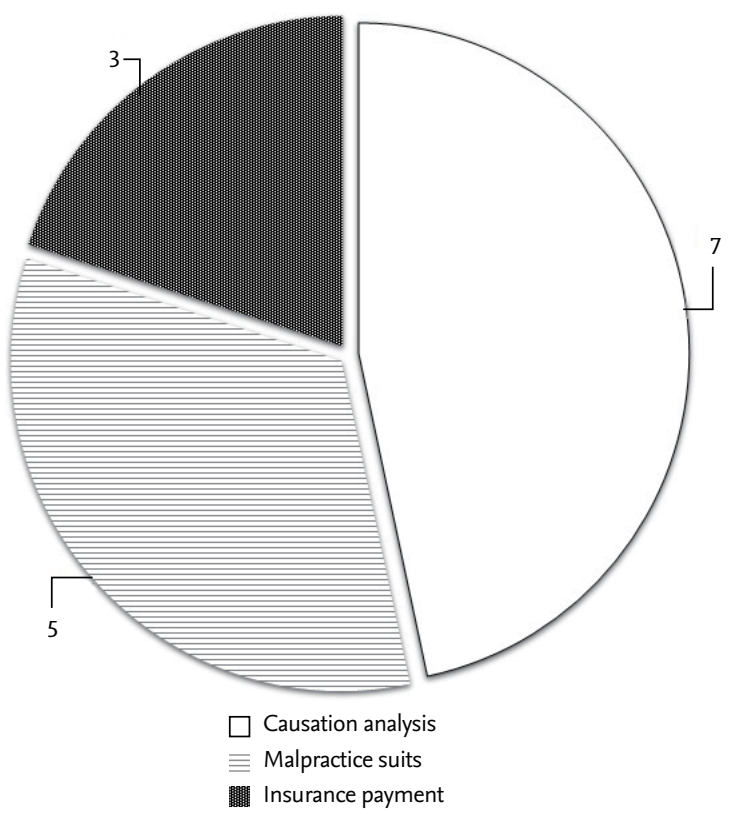

Fig. 1. Subjective distribution of precedents related to cerebral aneurysms. as work-relationship. Five precedents were malpractice suits related to bad results or complications. Remaining three precedents were related to the insurance payment (Fig. 1).

Precedents related to the causation analysis included five industrial insurance cases and two pension cases for public officials. The court approved the work-relationship of aneurysmal rupture in two public officials and four industrial workers. The High Court denied the work-relationship of subarachnoid hemorrhage in a chairman of a labor union, since the work of a labor union was different from the proper work of the industry.

In five malpractice precedents, two precedents $(2009 \mathrm{Na}$ 75088, 2011Da36848) of the Supreme Court reversed former two precedents of the High Court (Table 1). The High Court initially approved the negligence of medical practitioner (2009Na75088). The doctor could not save the patient with a ruptured giant fusiform middle cerebral artery aneurysm. The aneurysm had been clipped before rupture about two years ago, however, it was grown and ruptured even after craniotomy with aneurysmal neck clipping. Since the patient's neurological status was deteriorating after the rupture, the High Court presumed earlier intervention might be needed for better outcome. However, the Supreme Court denied the negligence, since timing of the surgery was up to the surgeon.

In a case of cerebral infarction after clipping for an un-ruptured middle cerebral artery aneurysm, the High Court approved the doctors' obligation of explanation (2010Na9306). Although a cerebral infarction from an un-ruptured aneurysm was exceptional, the doctor had an obligation of explanation for the occurrence of such a complication. However, the Supreme Court reversed the judgment, since it was hard to explain an unpredictable complication (2011Da36848).

Table 1. Brief summary of five malpractice precedents

\begin{tabular}{|c|c|c|c|c|}
\hline Date & Code & Type & Brief results of judgment & Court \\
\hline January 10, 2003 & 2001Do 3292 & $\begin{array}{l}\text { Professional } \\
\text { negligence }\end{array}$ & Denied professional negligence & Supreme court \\
\hline October 21, 2010 & 2009Na 75088 & $\begin{array}{l}\text { Damage suit } \\
\text { (medical) }\end{array}$ & $\begin{array}{l}\text { Approved professional negligence (limit 15\%), denied } \\
\text { violation of liability for explanation }\end{array}$ & High court (Seoul) \\
\hline April 7, 2011 & 2010Na 9306 & $\begin{array}{l}\text { Damage suit } \\
\text { (medical) }\end{array}$ & $\begin{array}{l}\text { Denied professional negligence, approved violation of } \\
\text { liability for explanation }\end{array}$ & High court (Busan) \\
\hline June 14,2012 & 2010Da 95635 & $\begin{array}{l}\text { Damage suit } \\
\text { (medical) }\end{array}$ & Denied professional negligence & Supreme court \\
\hline February 2, 2013 & 2011Da 36848 & $\begin{array}{l}\text { Damage suit } \\
\text { (medical) }\end{array}$ & Denied violation of liability for explanation & Supreme court \\
\hline
\end{tabular}


In a case of spontaneous subarachnoid hemorrhage (2001Do3292), the internist could not make a correct diagnosis. The Supreme Court denied the accidental infliction of injury, which was approved in the initial judgment.

The remaining three precedents were related to the insurance payment. In a patient with subarachnoid hemorrhage with concomitant facial injury, the court approved the accident. In a patient with delayed traumatic cerebral hemorrhage, the court approved the accident, too. However, the court denied the accident in a patient with aneurysmal hemorrhage, although the rupture was happened after hair-washing in a cold stream.

\section{DISCUSSION}

The main reasons of the suits were related to causation analysis, such as work-relationship in seven precedents, civil suits on medical disputes in five precedents, and interpretation of insurance clauses in three precedents. Of course, the number of judicial precedents does not mean the actual number of suits. However, precedents are regarded as standards of care for given medical services under a variety of scenarios ${ }^{4)}$.

In seven precedents of causation analysis, the work-relationship was approved in two public officials and four industrial workers. In cases of pension for public officials or industrial insurance, the work-relationship was usually approved in strokes from either aneurysm or other vascular disorders, when the patient was overworked. The High Court denied the work-relationship, since the chairman of a labor union worked for the union all day, he did not participate in the proper work of the industry.

Neurosurgery remains a high-risk specialty in regard to malpractice litigation $^{2,6,7)}$. A failure to diagnose or to treat in a timely manner were the two most commonly cited reasons for litigation ${ }^{6}$. In five malpractice precedents, the Supreme Court denied the negligence of medical practitioner and the doctors' obligation of explanation. Earlier intervention might result better outcome, especially in a deteriorating patient, however, the Supreme Court regarded the timing of surgery as a discretionary power. In a case of unpredictable cerebral infarction (2010Na9306), an independent medical examiner provided an important medical information, i.e., cerebral infarction was common in ruptured aneurysms (36 cases in 177), even in un- ruptured aneurysms (2 cases in 94) (http://glaw.scourt.go.kr/ wsjo/panre/sjol00.do?contId=2115179\&q=\%EB $\% 87 \% 8 \mathrm{C} \% \mathrm{E}$ B\%8F\%99\%EB\%A7\%A5\%EB\%A5\%98\&nq=\&w=panre\&s ection $=$ panre_tot $\&$ subw $=\&$ subsection $=\&$ subId $=2 \& \operatorname{csq}=\& \mathrm{~g}$ roups $=6,7,5,9 \&$ category $=\&$ outmax $=1 \&$ msort $=\&$ onlycount $=$ $\& \mathrm{sp}=\& \mathrm{~d} 1=\& \mathrm{~d} 2=\& \mathrm{~d} 3=\& \mathrm{~d} 4=\& \mathrm{~d} 5=\& \mathrm{pg}=9 \& \mathrm{p} 1=\& \mathrm{p} 2=\& \mathrm{p} 3=$ $\& \mathrm{p} 4=\& \mathrm{p} 5=\& \mathrm{p} 6=\& \mathrm{p} 7=\& \mathrm{p} 8=\& \mathrm{p} 9=\& \mathrm{p} 10=\& \mathrm{p} 11=\& \mathrm{p} 12=\& \mathrm{~s}$ $\mathrm{sCd}=$ WSJO\&tabGbnCd=\&saNo $=\& j o \mathrm{No}=\& \mathrm{lawNm}=\&$ hanja $\mathrm{Yn}=\mathrm{N} \&$ userSrchHistNo $=$ \&poption $=\& \operatorname{srch}=\&$ range $=\&$ daew byn $=$ N\&smpryn=N\&tabId $=0$ ). The Supreme Court limited doctors' obligation of explanation when the complications were unpredictable. One precedent of the Supreme Court also denied the accidental infliction of injury negligence in misdiagnosis of subarachnoid hemorrhage. Among all patients with headache who presented to emergency departments, have found that approximately one percent had subarachnoid hemorrhage ${ }^{5,9)}$. Despite the widespread availability of neuroimaging equipment, misdiagnosis of subarachnoid hemorrhage remains common, and it is an important cause of litigation ${ }^{3,5)}$. Misdiagnosis of subarachnoid hemorrhage might not be below the standard care of expected of the internist, however, it might be below the standard for a reasonable neurologist or a neurosurgeon.

In medical litigations, the role of the expert witness is very important, since judges don't have any medical knowledge. Doctors who serve as expert witnesses have an obligation to present complete, accurate, and unbiased information ${ }^{8,12)}$. In Korea, independent medical examiners usually provide such medical information, however, we don't have any guidelines or educational programs for medical expert witness testimony. Automatic mediation would increase medical disputes and requirement of independent medical examination. Doctors should prepare to the trend of medico-legal environment. We should look our medico-legal environment. Tort liability is unfamiliar territory to doctors trained in the rational sciences and arts of healing and accustomed to professional relationships of trust, respect, and kindness ${ }^{1)}$. Most doctors feel intense strain when faced with a lawsuit, however, it is a verbal contact sport, with winners and losers ${ }^{1,11)}$. We should learn strategies for surviving a malpractice lawsuit ${ }^{11)}$. We also need a guideline or educational programs for the independent medical examination.

In high-risk fields such as neurosurgery, frequent medical dispute mediation would bring defensive medicine ${ }^{13)}$. Defen- 
sive medicine is a public health issue that affects clinical decision making and contributes to rising health care costs ${ }^{2,13)}$.

The remaining three precedents were related to the insurance payment. A customer subscribed to Disaster agencies insurance can receive payout twice to five times, when he said the cause was an accident. If the customers subscribed to a Sickness rider insurance, payout would be only a fifth to half of the former at the same situation. Interpretation of the causation or differentiation of an injury from disease can be an important issue in the insurance payment. Although hairwashing in a cold stream might be a disaster, the court denied the accident in a patient with aneurysmal hemorrhage.

\section{CONCLUSION}

Judicial precedents on cerebral aneurysms included not only malpractice suits, but also causation analysis or insurance payment. Attention to these subjects is needed. We also need a guideline or educational programs for the independent medical examination. To avoid medical disputes, shared decision making seems to be useful, especially in cases of high risk condition or high risk procedures.

\section{CONFLICTS OF INTEREST}

No potential conflict of interest relevant to this article was reported.

\section{INFORMED CONSENT}

Informed consent was obtained from all individual participants included in this study.

\section{References}

1. Bean JR : Defensive medicine: rational response to irrational risk. World Neurosurg 94 : 568-569, 2016

2. Bekelis K, Missios S, Wong K, MacKenzie TA : The practice of cranial neurosurgery and the malpractice liability environment in the United States. PloS One 10 : e0121191, 2015

3. Bird S : Failure to follow up CT reports. Aust Fam physician 36 : 949950, 2007

4. Chodos JE : Should there be specialty courts for medical malpractice litigation? Col Med Rev 1 : 10-22, 2015

5. Edlow JA, Caplan LR : Avoiding pitfalls in the diagnosis of subarachnoid hemorrhage. N Engl J Med 342 : 29-36, 2000

6. Gupta R, Griessenauer CJ, Moore JM, Adeeb N, Patel AS, Ogilvy CS, et al. : An analysis of malpractice litigation related to the management of brain aneurysms. J Neurosurg 127 : 1077-1083, 2017

7. Jena $A B$, Seabury $S$, Lakdawalla D, Chandra A : Malpractice risk according to physician specialty. N Engl J Med 365 : 629-636, 2011

8. Paul SR, Narang SK; Committee on Medical Liability and Risk Management : Expert witness participation in civil and criminal proceedings. Pediatrics 139 : e20163862, 2017

9. Ramirez-Lassepas M, Espinosa CE, Cicero JJ, Johnston KL, Cipolle RJ, Barber DL : Predictors of intracranial pathologic findings in patients who seek emergency care because of headache. Arch Neurol 54 : 15061509, 1997

10. Rovit RL, Simon AS, Drew J, Murali R, Robb J : Neurosurgical experience with malpractice litigation: an analysis of closed claims against neurosurgeons in New York State, 1999 through 2003. J Neurosurg 106 : 1108-1114, 2007

11. Sheridan $A$ : You are not alone: ten strategies for surviving a malpractice lawsuit. Perm J 20 : 107-108, 2016

12. Shim JH, Lee KS, Shim JJ, Yoon SM, Doh JW, Bae HG : Analysis of precedents related to the medical accidents of neurosurgery. Korean J Neurotrauma 8 : 32-36, 2012

13. Yan SC, Hulou MM, Cote DJ, Roytowski D, Rutka JT, Gormley WB, et al. : International defensive medicine in neurosurgery: comparison of Canada, South Africa, and the United States. World Neurosurg 95 : 53-61, 2016 